\title{
THE PHOTOGRAPHIC EMULSION: THE MECHANISM OF HYPERSENSITIZATION
}

\author{
By Burt H. Carroll and Donald Hubbard
}

\section{ABSTRACT}

Confirming earlier work at the Bureau of Standards, hypersensitization by bathing with ammonia is shown to consist of a selective increase in sensitivity for the spectral region of sensitization by the dye. Hypersensitization by a given solution is highly dependent on the dye and to a less extent on the emulsion; for many commercial panchromatic emulsions, water is preferable to ammonia solutions for practical use. On bathing a photographic emulsion in a solution there is set up a membrane equilibrium which is shown by electrode measurements to obey the Donnan equation. As a result of an almost unique combination of properties, bathing with ammonia and drying leaves an emulsion with an excess of silver over halogen; this is confirmed by chemical analysis of plates and baths used for hypersensitization. Comparison of data on the effect of ammonia on sensitization by known dyes with those of Research Paper 488 on the effect of silver ion concentration in the emulsion on the same dyes shows very close correspondence. There is satisfactory correlation between the photographic effects of ammonia treatment and those of excess silver in the emulsion; other theories of hypersensitization, which are discussed briefly are shown to be inadequate. Reports of hypersensitization by hydrogen peroxide are shown to be the result of inadequate control experiments, but appreciable hypersensitization by reducing agents was confirmed.

\section{CONTENTS}

I. The phenomena of hypersensitization

II. The equilibrium between photographic emulsions and ammonia solutions

III. Correlation of the chemical and sensitometric data on hypersensitization.

IV. Acknowledgment

V. List of references

\section{THE PHENOMENA OF HYPERSENSITIZATION}

Silver halides emulsified in gelatin selectively absorb radiation of the shorter wave lengths; for bromiodide, the absorption is very small for wave lengths greater than $500 \mathrm{~m} \mu$, and for other halides the limit is shorter. Photographic sensitivity necessarily corresponds to the absorption. As discovered by Vogel in 1876, certain dyes which absorb the longer wave lengths may sensitize silver halide emulsions for these regions. This increase in sensitivity for the region absorbed by the dye is, however, almost invariably accompanied by a decrease in the short wave length sensitivity of the emulsion. The magnitudes of both these changes are involved in a determination of the effectiveness of sensitization in a given case. In the comparison of the sensitization of a given emulsion by a given dye under varying conditions, which was the principal determination 
made in the experiments described in this paper and in our preceding communication (Research Paper No. 488) we found two of the three possible general types of change. Long and short wave length sensitivity may increse or decrease together, the change in the ratio of sensitivity to the two regions being less than the changes in absolute values. The long wave length sensitivity may increase or decrease with relatively constant short wave length sensitivity, and correspondingly large changes in relative spectral sensitivity. The third case of constant long wave length sensitivity and varying short wave length sensitivity has not been encountered. Change in the absolute values of sensitivity for both long and short wave lengths with constant relative spectral sensitivity was first reported by Sheppard (1) ${ }^{1}$ as a result of sensitization by allyl thiocarbamide, or desensitization by chromic acid, these procedures involving, respectively, the formation and destruction of sensitivity nuclei. The writers have found similar effects (2), although the fractional change in long wave length sensitivity was generally the smaller. Changes in hydrogen ion, or even more in silver ion concentration in the emulsion (2) tend to increase the long wave length sensitivity with little change in the short wave length sensitivity. In contrast to the first case, the relative spectral sensitivity is greatly changed.

The discovery that sensitization by a dye could be improved by changing conditions in the emulsion was first made by Schumann (3), who found that a preliminary bath of ammonia improved sensitization by cyanine; in spite of numerous other suggestions, ammonia is still the most important hypersensitizing agent. We shall use the term "hypersensitization" to cover any case in which increase in sensitization by a dye is produced by treatment with a material itself colorless or absorbing a spectral region different from that of the dye. The term has been most commonly applied to after treatment of plates or films sensitized in the emulsion, but the mechanism appears to be the same whether the hypersensitizing agent is applied before, with or after the dye, and there is generally little difference in the magnitude of the effect.

Hypersensitization of course implies an increase in sensitivity to the longer wave lengths. . In spite of the numerous investigations of the subject, there is still some dispute as to whether the sensitivity for the shorter wave lengths is normally increased. In the latest edition of Eder's Ausführliches Handbuch der Photographie, Dieterle (4) states that the change in this region is relatively small. Experiments at this bureau (5) (6) have been in entire agreement that hypersensitization normally involves a great increase in relative sensitivity to the longer wave-lengths; the data of Walters and Davis $(6)^{2}$ are particularly clear on this point. However, Wall (7) reported that in a "long series of experiments where there was socalled increased color sensitiveness, there was also increased general sensitivity, and if the ratio of the blue to the color sensitiveness was taken into account, there was practically no increase in the same." We are, therefore, including in this paper data which demonstrate that in our experiments hypersensitiz ation always involved an increase in relative sensitivity to the longer wave lengths.

1 Numbers in parentheses here and throughout the text refer to the list of references at the end of the article. 
These data also show a fact which has been imperfectly understood: That a given treatment may produce marked hypersensitization in one plate or film, and none in another. These differences are to be attributed primarily to the dye and secondarily to the emulsion. The data of Walters and Davis (6) for example, show clearly that the isocyanine dyes, pinaverdol, and orthochrome $T$, were hypersensitized very little by ammonia, while it produced a large effect on sensitization by pinacyanol, and a still larger one on sensitization by dicyanine. Jacobsohn (8) has reported that a neutral emulsion could be readily hypersensitized by ammonia, while a comparable emulsion made by the ammonia process could not. Other illustrations could be given, but these will serve to make the point that it is impossible to say that a given bath will or will not cause bypersensitization without specifying the dye and emulsion. Some of the confusion on this point has probably risen from the varying requirements of users; in certain types of spectrography, for example, all other properties may be sacrificed to sensitivity, and it is possible to work with plates having fog which would be intolerable for pictorial use. The use of various methods of testing, some of them quite imperfect, have added to the misunderstandings.

The most serious error in some studies of hypersensitization has been the lack of adequate controls. The great majority of panchromatic emulsions are considerably improved in sensitivity to the longer wave lengths simply by washing with water ((6) and Table 1). It is therefore essential that the hypersensitizing action of any solution should be compared with that of water, under the same conditions of bathing and drying. If the emulsion is compared only without treatment, and after treatment with a given solution, effects which are actually caused only by the water of the solution may be ascribed to the dissolved substance.

In these experiments, sensitivity was determined by nonintermittent exposure in the sector-wheel sensitometer through appropriate filters to isolate spectral regions absorbed by the dye and by the silver halide. In a few cases, the sensitivity conferred by the dye was such a small fraction of the total that exposure to white light could be substituted for exposure to blue light without serious error. Sensitivity has been reported in terms of speed numbers $(10 / i)^{2}$ corresponding to development to a constant $\gamma$. This was 1.0 , unless the emulsion was of high contrast, when a value in the working range was chosen.

The plates or films were bathed for about three minutes at a temperature of $10^{\circ}$ to $15^{\circ} \mathrm{C}$. with constant rocking, and dried in a rapid current of air. The drying should be rapid. Unless the air temperature is less than $25^{\circ} \mathrm{C}$. and the humidity at a low relative valuesuch as exists in heated rooms in cold weather, it is desirable to accelerate the drying by soaking the plate in alcohol for a few minutes after bathing. This treatment unfortunately can not be applied to most films. The entire emulsion surface was exposed to the air current in our drying apparatus; it is important that no part of it

In the values of inertia (i) no correction was made for the absorption by the filter, so that the speed numbers are comparative only. This results, for example, in low values of speed numbers for blue light, since the transmission of the "C" filter is not over 27 per cent for any wave length. 
should be shielded by the plate rack or other obstruction if the dried plate is to be uniform in sensitivity.

Table 1 gives data on the hypersensitization of six fast commercial panchromatic emulsions. Similar data for another emulsion may be found in the control experiments recorded in the first three lines of Table 7. Exposures to "blue" light were made through the Wratten C filter, those to "red" light through the Wratten A, in both cases in addition to the Davis-Gibson correction filter. In three cases, plate $\mathrm{B}$ and films $\mathrm{B}$ and $\mathrm{C}$, two emulsion numbers are represented in the comparisons of the washed emulsion with the untreated and ammonia-treated emulsion, respectively.

TABLE 1.-Hypersensitization of commercial panchromatic plates and films

\begin{tabular}{|c|c|c|c|c|c|c|}
\hline \multirow{2}{*}{ Emulsion } & \multirow{2}{*}{ Bath } & \multicolumn{2}{|c|}{\begin{tabular}{|c|} 
Halide extracted \\
by bath, molar \\
ratio to $\mathbf{A g B r}$ \\
$\times 1,000$
\end{tabular}} & \multicolumn{2}{|c|}{ Speed at $\gamma=1.0$} & \multirow{2}{*}{$\begin{array}{l}\text { Fog for } \\
6 \text {-min- } \\
\text { ute de- } \\
\text { velop- } \\
\text { ment }\end{array}$} \\
\hline & & $\mathrm{Br}-$ & $\mathrm{Cl}-$ & $\begin{array}{l}\text { Red } \\
\text { light }\end{array}$ & $\begin{array}{l}\text { Blue } \\
\text { light }\end{array}$ & \\
\hline Plate A.. & $\left\{\begin{array}{l}\text { None-1- } \\
\text { Water- } \\
0.05 \mathrm{~N} \mathrm{~N} \mathrm{NH}_{3-}\end{array}\right.$ & $\begin{array}{l}5.2 \\
7.5\end{array}$ & $\begin{array}{l}10.5 \\
11.6\end{array}$ & $\begin{array}{r}82 \\
173 \\
195\end{array}$ & $\begin{array}{l}74 \\
57 \\
58\end{array}$ & $\begin{array}{r}0.39 \\
.41 \\
.44\end{array}$ \\
\hline $\begin{array}{l}\text { Plate B: } \\
\quad \text { Emulsion 2..- }\end{array}$ & $\left\{\begin{array}{l}\text { None-....... } \\
\text { Water-. }\end{array}\right.$ & 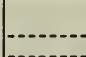 & 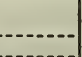 & $\begin{array}{l}43 \\
85\end{array}$ & $\begin{array}{l}35 \\
31\end{array}$ & .28 \\
\hline Emulsion 1... & $\left\{0.25 \mathrm{~N} \mathrm{NH}_{3-}\right.$ & $\begin{array}{l}1.6 \\
8.4\end{array}$ & $\begin{array}{l}64 \\
63\end{array}$ & $\begin{array}{l}42 \\
59\end{array}$ & $\begin{array}{l}13 \\
19\end{array}$ & .27 \\
\hline Plate C.. & 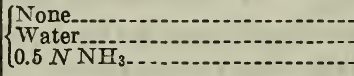 & $\begin{array}{r}.7 \\
5.2\end{array}$ & $\begin{array}{l}0 \\
0\end{array}$ & $\begin{array}{l}15.5 \\
17 \\
51.5\end{array}$ & $\begin{array}{l}20.5 \\
22 \\
39\end{array}$ & $\begin{array}{l}.21 \\
.23 \\
.42\end{array}$ \\
\hline Film A. & 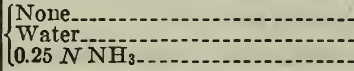 & $\begin{array}{r}5.8 \\
15.4\end{array}$ & $\begin{array}{l}38 \\
38\end{array}$ & $\begin{array}{l}17 \\
51 \\
50\end{array}$ & $\begin{array}{l}34 \\
-50\end{array}$ & $\begin{array}{l}.23 \\
.23 \\
.29\end{array}$ \\
\hline $\begin{array}{l}\text { Film B: } \\
\text { Emulsion 1... }\end{array}$ & None & & 5 & 23 & 37 & .23 \\
\hline Emulsion 2-... & $\left\{\begin{array}{l}0.00 \\
0.25 \mathrm{NH}\end{array}\right.$ & $\begin{array}{r}8.8 \\
17.6\end{array}$ & $\begin{array}{l}38 \\
35\end{array}$ & $\begin{array}{r}60 \\
100\end{array}$ & $\begin{array}{l}43 \\
60\end{array}$ & .21 \\
\hline $\begin{array}{l}\text { Film C: } \\
\text { Emulsion 2 }\end{array}$ & $\left\{\begin{array}{l}\text { None--.... } \\
\text { Water }\end{array}\right.$ & 4.5 & 13 & $\begin{array}{l}40 \\
70\end{array}$ & 38 & .19 \\
\hline Emulsion 1.-- & $\left\{\begin{array}{l}-\mathrm{do} \\
0.25 \mathrm{~N}\end{array}\right.$ & $\begin{array}{r}3.7 \\
17.3\end{array}$ & $\begin{array}{l}0 \\
0\end{array}$ & $\begin{array}{r}57 \\
100\end{array}$ & $\begin{array}{l}40 \\
30\end{array}$ & .21 \\
\hline
\end{tabular}

Several observations may be made on these data. In the first place, the increase in red-light speed was invariably greater than the increase in blue-light speed, so that the relative sensitivity to the longer wave lengths increased. This is in agreement with previous experiments at this bureau, and in contradiction to Wall's statement. The sensitivity to blue light normally was increased, ${ }^{3}$ but the increase was comparable with that in red-light speed in only two cases (ammonia treatment of $\mathrm{pl} . \mathrm{B}$ and film $\mathrm{B}$ ).

The second point of interest is that treatment with water alone was almost as effective as the use of ammonia solutions, with the one ex-

\footnotetext{
Pl. A shows the unusual and unexplaiued effect of a decrease in sensitivity to blue light on washieg; the change is smull, hut apparently real. The decrease in flm $\mathrm{C}$ on ammonis treatmont is obviously the result of the heavy fog which was produced.
} 
ception of plate C. ${ }^{4}$ The difference between water and ammonia was much more marked for the panchromatic emulsions tested by Walters and Davis (6) and for some of our experimental emulsions sensitized with known dyes, recorded in Tables 2, 3, and 5. Spectrograms indicate that the dyes now used for sensitization are different from those in use only a few years ago. As the use of water involves less risk of causing fog than the use of ammonia, especially if the plates are to be kept any time after bathing, it is preferable for most cases. The increase in speed which is obtainable even from the fastest panchromatic emulsions by simple bathing with cold water is evident from the data.

TABLE 2.-Hypersensitization of experimental emulsion 4-148

[Speed numbers are relative only, the correction filter having been omitted in these tests; all values are for development to $\gamma=1.0]$

\begin{tabular}{|c|c|c|c|c|}
\hline \multirow{3}{*}{$x^{2+2}$} & \multirow{3}{*}{ Bath } & \multicolumn{3}{|c|}{ Speed numbers } \\
\hline & & \multirow{2}{*}{$\begin{array}{c}\begin{array}{c}\text { Unsensi- } \\
\text { tized emul- } \\
\text { sion }\end{array} \\
\begin{array}{c}\text { Blue-light } \\
\text { exposure }\end{array}\end{array}$} & \multicolumn{2}{|c|}{$\begin{array}{c}\text { Pinacyanol-sensitized } \\
\text { emulsion }\end{array}$} \\
\hline & & & $\begin{array}{l}\text { Blue-light } \\
\text { exposure }\end{array}$ & $\begin{array}{l}\text { Red-light } \\
\text { exposure }\end{array}$ \\
\hline \multicolumn{2}{|c|}{ 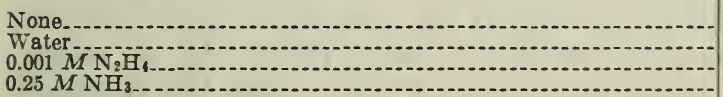 } & $\begin{array}{l}18.5 \\
22 \\
27 \\
63\end{array}$ & $\begin{array}{l}12.5 \\
17 \\
179 \\
39\end{array}$ & $\begin{array}{r}70 \\
185 \\
250 \\
800\end{array}$ \\
\hline
\end{tabular}

TABLE 3.-Hypersensitization of experimental emulsion $4-145$

[Speed numbers are relative only, the correction filter having been omitted in these tests; all values are for development to $\gamma=1.0]$

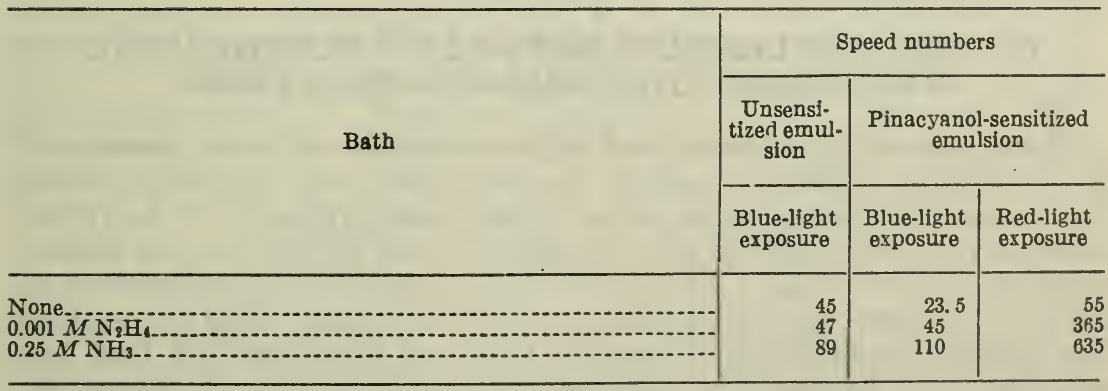

The magnitude of the change in sensitivity to blue light is of considerable importance in deciding on the mechanism of hypersensitization. In panchromatic emulsions, it is generally larger than would be expected from the fact that many unsensitized emulsions are practically unaffected by washing or ammonia treatment. Moderate speed commercial emulsions (Seeds 23, Eastman 33 and 36), and comparable experimental emulsions showed no increase in speed on bathing in ammonia, although other unsensitized experimental emul-

- Reference to column 3 shows that pl. C contained an urusually small smount of soluble bromide. This accounts for the constant sensitivity on washing. The data on bromide extracted by the smmonis solutions will be discussed later in the paper. The increase in red-light speed of film C on ammonia treatment was accompanied by an increase in fog which made tho film practically useless. 
sions have given positive results. The experiments recorded in Tables 2 and 3 demonstrate that the sensitizing dye changes sensitivity to blue light, although it does not sensitize for this region. The emulsions used for these experiments were made by the neutral process, differing only in that the silver iodide was 1 per cent of the total silver in 4-143 and 4 per cent in 4-145. After washing, potassium bromide in the molecular ratio of $5 \mathrm{KBr}$ per $1,000 \mathrm{AgBr}$ was added to each emulsion, and they were digested to rather less than maximum sensitivity. Each emulsion was coated in two portions, one unsensitized and the other with the addition of pinacyanol. After drying, plates were treated as indicated in the tables and tested. The tables show that the pinacyanol, plus the soluble bromide, reduced the sensitivity of the emulsions to blue light. On washing with water which removed the soluble bromide, the blue-light sensitivity of the pinacyanol-sensitized portions was restored to the original value; that of the unsensitized portion was only slightly increased, as would be anticipated from the relatively small effect of silver ion concentration on sensitivity in the absence of dyes (9). The increase in blue-light sensitivity on washing the commercial emulsions recorded in Table 1 may therefore be interpreted as the removal of a desensitizing effect, since all dyes in the presence of bromide cause some desensitization to the blue. Emulsions 4-143 and 4-145 (Tables 2 and 3), probably because of incomplete digestion, increased in speed on ammonia treatment of the unsensitized portions; the blue-light speed of the sensitized portions increased in about the same ratio. In all cases, the increase in red-light speed was much greater than the increase in blue-light speed.

In order to understand the photographic effects produced by bathing with ammonia, it will be necessary first to consider the chemical equilibrium set up by this process.

\section{THE EQUILIBRIUM BETWEEN PHOTOGRAPHIC EMIULSIONS AND AMMONIA SOLUTIONS}

If two solutions are separated by a membrane which is permeable to the solutes, diffusion through the membrane will ultimately bring the concentrations on both sides to the same values. If, however, there is present in one of the solutions an ion which can not diffuse through the membrane, this will result in an uneven distribution of all the ions between the two sides of the membrane when the system has reached equilibrium. Donnan (10) has demonstrated that the equilibrium is governed by the relation that the ratios of concentrations of all diffusible univalent ions of the same sign, on the two sides of the membrane shall be the same, and that the product of the concentrations of any pair of (univalent) positive and negative ions on one side of the membrane shall be the same as the product of the concentrations on the other side.

When a jelly, such as a photographic emulsion, is immersed in a solution, the Donnan equation may be applied to the concentrations of the solution inside and outside the jelly. Let us consider first the case of an emulsion of pure $A g B r$ in gelatin bathed in a solution of an alkali, such as $N a O H$. The gelatin is permeable to all the ions of $\mathrm{NaOH}$ and $\mathrm{AgBr}$, so that all four of these will be found both inside and outside the emulsion at equilibrium. However, the gelatin 
combines with $\mathrm{OH}^{-}$to form a negatively charged complex which acts as a nondiffusible ion present only inside the gelatin and thus causes an uneven distribution.

According to Donnan's equation

$\left[\mathrm{OH}^{-}\right]_{o}=\left[\mathrm{Br}^{-}\right]_{o}=\frac{\left[\mathrm{Na}^{+}\right]_{i}}{\left[\mathrm{OH} \mathrm{Hg}^{+}\right]_{i}}$ (where the subscripts $i$ and $o$ indicate $\left[\mathrm{OH}^{-}\right]_{i}=\frac{\left.\mathrm{Br}^{-}\right]_{i}}{\left[\mathrm{Ba}_{0}\right]_{o}}=\frac{[\mathrm{Ng}]_{o}}{\left[\mathrm{Ag}^{+}\right.}$the inside and outside solutions, respectively)

$\left[\mathrm{OH}^{-}\right]_{o}>\left[\mathrm{OH}^{-}\right]_{i}$ because of the combination of $\mathrm{OH}^{-}$and gelatin, so that

$$
\left[\mathrm{Ag}^{+}\right]_{i}>\left[\mathrm{Ag}^{+}\right]_{o} \text { and }\left[\mathrm{Br}^{-}\right]_{i}<\left[\mathrm{Br}^{-}\right]_{0}
$$

The excess of positively charged diffusible ions in the gelatin is electrically balanced by the negative (gelatin $O H)^{-}$complex, and $\left[\mathrm{Ag}^{+}\right]_{i}>\left[\mathrm{Br}^{-}\right]_{i}$. If the emulsion is removed from the solution and dried, it will be left with an excess of $\mathrm{Ag}^{+}$over $\mathrm{Br}^{-}$, the excess $\mathrm{Ag}^{+}$ being in combination with the gelatin (11); the solution will contain an excess of bromine over silver, since these were originally in equivalence in the emulsion.

Silver bromide being very difficultly soluble, the quantities involved are very small, and it is only by repeated extraction that any considerable excess of silver can be left in the emulsion. If, however, ammonia is substituted for the simple alkali, the solubility of silver bromide is so increased that much larger effects may be produced. The equilibrium is essentially the same although complicated by the second equilibrium

$$
\frac{\left[\mathrm{Ag}^{+}\right] \times\left[\mathrm{NH}_{3}\right]^{2}}{\left[\mathrm{Ag}\left(\mathrm{NH}_{3}\right)_{2}{ }^{+}\right]}=K
$$

which results in a decrease in $\left[\mathrm{Ag}^{+}\right]$to a very small value, with corresponding increase in $\left[\mathrm{Br}^{-}\right]$to maintain the condition that $\left[\mathrm{Ag}^{+}\right] \times$ $\left[\mathrm{Br}^{-}\right]=S$ (solubility product of $\mathrm{AgBr}$ ). The principal ions in the outside solution are therefore $\mathrm{Ag}\left(\mathrm{NH}_{3}\right)_{2}{ }^{+}, \mathrm{NH}_{4}^{+}, \mathrm{Br}^{-}$, and $\mathrm{OH}^{-}$. The same ions, plus the nondiffusible (gelatin-OH) ${ }^{-}$, are present inside.

$$
\frac{\left.\left[\mathrm{Ag}\left(\mathrm{NH}_{3}\right)_{2}\right]_{i}\right]_{i}}{\left[\mathrm{Ag}\left(\mathrm{NH}_{3}\right)_{2}\right]_{o}}=\frac{\left[\mathrm{NH}_{4}^{+}\right]_{i}}{\left[\mathrm{NH}_{4}^{+}\right]_{o}}=\frac{\left[\mathrm{Br}^{-}\right]_{o}}{\left[\mathrm{Br}^{-}\right]_{i}}=\frac{\left[\mathrm{OH}^{-}\right]_{o}}{\left[\mathrm{OH}^{-}\right]_{i}}
$$

Ammonia being alkaline, we have, as before, that $\left[\mathrm{OH}^{-}\right]_{o}>\left[\mathrm{OH}^{-}\right]_{i}$ and consequently that $\left[\mathrm{Ag}\left(\mathrm{NH}_{3}\right)_{2}{ }^{+}\right]_{t}>\left[\mathrm{Ag}\left(\mathrm{NH}_{3}\right)_{2}{ }^{+}\right]_{o}$ and $\left[\mathrm{Ag}\left(\mathrm{NH}_{3}\right)_{2}{ }^{+}\right]_{i}$ $>\left[\mathrm{Br}^{-}\right]_{i}$. The concentrations of $\mathrm{Ag}\left(\mathrm{NH}_{3}\right)_{2}{ }^{+}$and $\mathrm{Br}^{-}$being much greater than those of $\mathrm{Ag}^{+}$and $\mathrm{Br}^{-}$in simple alkali solutions, an emulsion bathed in an ammonia solution is left with an appreciable excess of $\mathrm{Ag}\left(\mathrm{NH}_{3}\right)_{2}{ }^{+}$over $\mathrm{Br}^{-}$. On drying the film the complex ion must decompose, since all known compounds of silver salts and ammonia are in equilibrium at room temperature only with ammonia pressures of the order of $100 \mathrm{~mm}$ of mercury. Before drying, the $\mathrm{Ag}\left(\mathrm{NH}_{3}\right)_{2}{ }^{+}$ ions had been electrically balanced by the negative gelatin ion, formed by combination of the gelatin and $\mathrm{OH}^{-}$ions. As the ammonia is removed, the remaining $\mathrm{Ag}^{+}$ions tend to combine with the gelatin ion. In the quantities formed by hypersensitization, the silver gelatin complex is in equilibrium (11) with a silver ion concentration enormously greater than that of the emulsion before treatment. A 
normal emulsion contains about $3 \times 10^{-3} \mathrm{~g}$ equivalent of $\mathrm{AgBr}$ per gram of gelatin; if 1 per cent of this is decomposed by the ammonia treatment, $3 \times 10^{-5} \mathrm{~g}$ equivalent of $\mathrm{Ag}^{+}$will be combined with $1 \mathrm{~g}$ of gelatin; this corresponds at $\mathrm{pH} 9$ with a silver ion concentration of $10^{-6} \mathrm{~N}$ as against $10^{-10} \mathrm{~N}$ in an average emulsion as coated. In an emulsion bathed with water alone, the final silver ion concentration will probably be less than one-tenth that produced by ammonia.

It will be noted that this final result is dependent on several conditions, which are fulfilled almost uniquely by ammonia and some of the amines. Ammonia gives an alkaline solution which dissolves silver salts by formation of a positively charged complex ion of silver, which breaks down on drying. If the complex ion containing the silver is negatively charged, as in cyanide, thiosulphate, sulphite or thiocyanate solutions, its distribution will follow the same ratio as the bromide ion and there will be no excess of silver left in the emulsion and no hypersensitization. ${ }^{5}$ A nonvolatile complex would also prevent the final rise in $\left[\mathrm{Ag}^{+}\right]_{i}$ on drying. The magnitude of the final effect will increase with increasing solubility of silver bromide, and consequently with increasing concentration of ammonia. The presence of soluble bromide reduces the effect of the ammonia, since $\left[\mathrm{Br}^{-}\right]_{t}$ may be greater than $\left[\mathrm{Ag}\left(\mathrm{NH}_{3}\right)_{2}{ }^{+}\right]_{t}$ if there is enough soluble bromide present, even though the ratios of inside and outside concentrations are the same as in the absence of soluble bromide. Conversely, the effect is increased by the addition of silver salts, such as the chloride or oxide, to the ammonia bath. An acid solution dissolving silver salts by formation of a volatile negative complex would produce the same effect as ammonia, but as far as we know, no such solution exists.

The applicability of the Donnan equation to equilibrium between silver bromide-gelatin emulsions and ammonia solutions was demonstrated experimentally. For quantitative results it was necessary to use liquid emulsion, separated from the ammonia solution by a membrane. Ion concentrations can not be measured in the set emulsion on a plate; and because of the volatility of the ammonia and the necessary change in temperature, it was also impracticable to bring the emulsion on a plate to equilibrium, then strip and melt it for measurements. Accordingly, $50 \mathrm{ml}$ samples of emulsions were placed in small sacks of goldbeater's skin or collodion which were surrounded with ammonia solution, the system being maintained at $30.0^{\circ} \mathrm{C}$. by an air thermostat. Stoppers into the sack and the outside vessel made it possible to insert into either one a silver-silver bromide electrode and salt bridge to determine the bromide ion concentration, or to remove samples of either solution. The readings taken with the electrode near the membrane were found to be somewhat uncertain, so that the final readings were all taken on samples which had been pipetted into a closed cell. The bromide ion concentration never became entirely constant, even after agitation for 24 hours or more, but the slow drift after this time was apparently caused by hydrolysis of the gelatin in the emulsion by the ammonia, with conse-

- One hypothesis as to the mechanism of hypersensitization was that it is caused by intragranular etching of the sllver hailde grains by the ammonia, with consequent exposure of fresh surface for the dye. LüppoCramer (12) tested this by adding one-half per cent $\mathrm{Na}_{2} \mathrm{SO}_{3}$ or $\mathrm{KSCN}$ to dye baths; we used $0.0034 \mathrm{~N} \mathrm{KCN}$, which is equivalent to $0.5 \mathrm{~N} \mathrm{NH}$, in solvent action for silver bromide. The negative results which were obtained could have been predicted from the failure of these baths to leave the emulsion with excess silver, and the strong adsorption of the anions of these solutions, which would tend to replace the basic dyes. 
quent formation of diffusible amino acids whose buffer action in the outside solution reduced the $\mathrm{pH}$ difference between the inside and outside; after the first day, the drift in electrode potential became less than $1 \mathrm{mv}$ per day. Readings were then taken on samples from the emulsion and the outside solution both with the silver-silver bromide electrode and the glass electrode (each being compared with a standard calomel electrode). We are indebted to M. R. Thompson, of the chemistry division of this bureau, for making the difficult measurements of hydroxyl ion concentration in these systems with the glass electrode.

If the equilibrium obeys the Donnan equation, then

$$
\frac{\left[\mathrm{Br}^{-}\right]_{0}}{\left[\mathrm{Br}^{-}\right]_{i}}=\frac{\left[\mathrm{OH}^{-}\right]_{0}}{\left[\mathrm{OH}^{-}\right]_{i}}
$$

Since the potential of either electrode is proportional to the logarithm of the corresponding ion concentration, if these two ratios are equal, the differences in potential of the two electrodes in the emulsion and the outside solution will be the same. The data in Table 4 show that this condition was fulfilled for both membrane materials and over a moderate range of conditions. The variations in the absolute values were caused by the concentration and volume of the emulsion samples and possibly by greater permeability of the collodion. Ammonia concentration was limited to about $0.05 \mathrm{~N}$ by the decreasing accuracy of the glass electrode at higher alkalinities.

TABLE 4.-Equilibrium between AgBr-gelatin emulsions and ammonia solutions (originally $0.050 \mathrm{~N}$ ) at $30.0^{\circ} \mathrm{C}$.

[Emulsions inside membrane, ammonia solution outside]

\begin{tabular}{|c|c|c|c|c|c|c|}
\hline \multirow{2}{*}{ Membrane } & \multicolumn{2}{|c|}{ [OH-] } & \multicolumn{2}{|c|}{$[\mathrm{Br}-]$} & \multicolumn{2}{|c|}{$\begin{array}{l}\text { Potential difference } \\
\text { of electrodes out- } \\
\text { side and inside } \\
\text { (in millivolts) }\end{array}$} \\
\hline & Outside & Inside & Outside & Inside & $\begin{array}{c}\text { Glass } \\
\text { electrode }\end{array}$ & $\begin{array}{l}\mathrm{Ag}-\mathrm{AgBr} \\
\text { electrode }\end{array}$ \\
\hline Gold bester's skin... & $\begin{array}{l}\text { 3. } 3 \times 10^{-1} \\
\text { 4. } 2 \times 10^{-1} \\
\text { 4. } 8 \times 10^{-4}\end{array}$ & $\begin{array}{l}1.12 \times 10^{-1} \\
1.20 \times 10^{-4} \\
1.31 \times 10^{-4}\end{array}$ & $\begin{array}{l}\text { 6. } 1 \times 10^{-1} \\
3.9 \times 10^{-1} \\
3.6 \times 10^{-1}\end{array}$ & $\begin{array}{l}2.0 \times 10^{-1} \\
8.6 \times 10^{-8} \\
7.2 \times 10^{-6}\end{array}$ & $\begin{array}{l}28 \\
31 \\
33\end{array}$ & $\begin{array}{l}29 \\
38 \\
41\end{array}$ \\
\hline Collodion. & $\begin{array}{l}3.5 \times 10^{-1} \\
2.4 \times 10^{-1} \\
4.0 \times 10^{-1}\end{array}$ & $\begin{array}{l}2.6 \times 10^{-1} \\
1.7 \times 10^{-1} \\
2.5 \times 10^{-4}\end{array}$ & $\begin{array}{l}2.3 \times 10^{-4} \\
2.7 \times 10^{-4} \\
2.4 \times 10^{-4}\end{array}$ & $\begin{array}{r}1.6 \times 10^{-1} \\
2.1 \times 10^{-4} \\
1.54 \times 10^{-1}\end{array}$ & $\begin{array}{r}7.6 \\
8.1 \\
11.6\end{array}$ & $\begin{array}{r}9.1 \\
6.1 \\
11.5\end{array}$ \\
\hline
\end{tabular}

The equilibrium was also studied under conditions comparable to photographic practice. Plates were bathed with constant rocking in ammonia solutions for three to five minutes, thereby approaching equilibrium within the limits of error of analysis, and the bath analyzed by electrometric titration. In order to eliminate the dissolved silver bromide from the solutions, the ammonia was either neutralized with acid or removed by evaporation; the two methods were found to agree within the limit of reproducibility of either one. The solution was then acidified to $\mathrm{pH} 2-3$ to prevent the trace of extracted protein from interfering with the end point, and titrated with $0.001 \mathrm{~N} \mathrm{AgNO}_{3}$ in the apparatus described in a previous com- 
munication (11). Electrometric titration is desirable, as many commercial emulsions contain soluble chloride in amounts as large as 10 molecules to 1 of soluble bromide; we have found the electrometric determination both simpler and more accurate than the possible purely chemical separations, such as the Lang method (13) (14). Figure 1 gives the results for extraction of Seed's 23 plates (emulsion $7,855)$ with varying concentrations of ammonia. These and subsequent data have been reduced to ratios of soluble bromide to silver bromide in the emulsion; the latter was determined by titration with

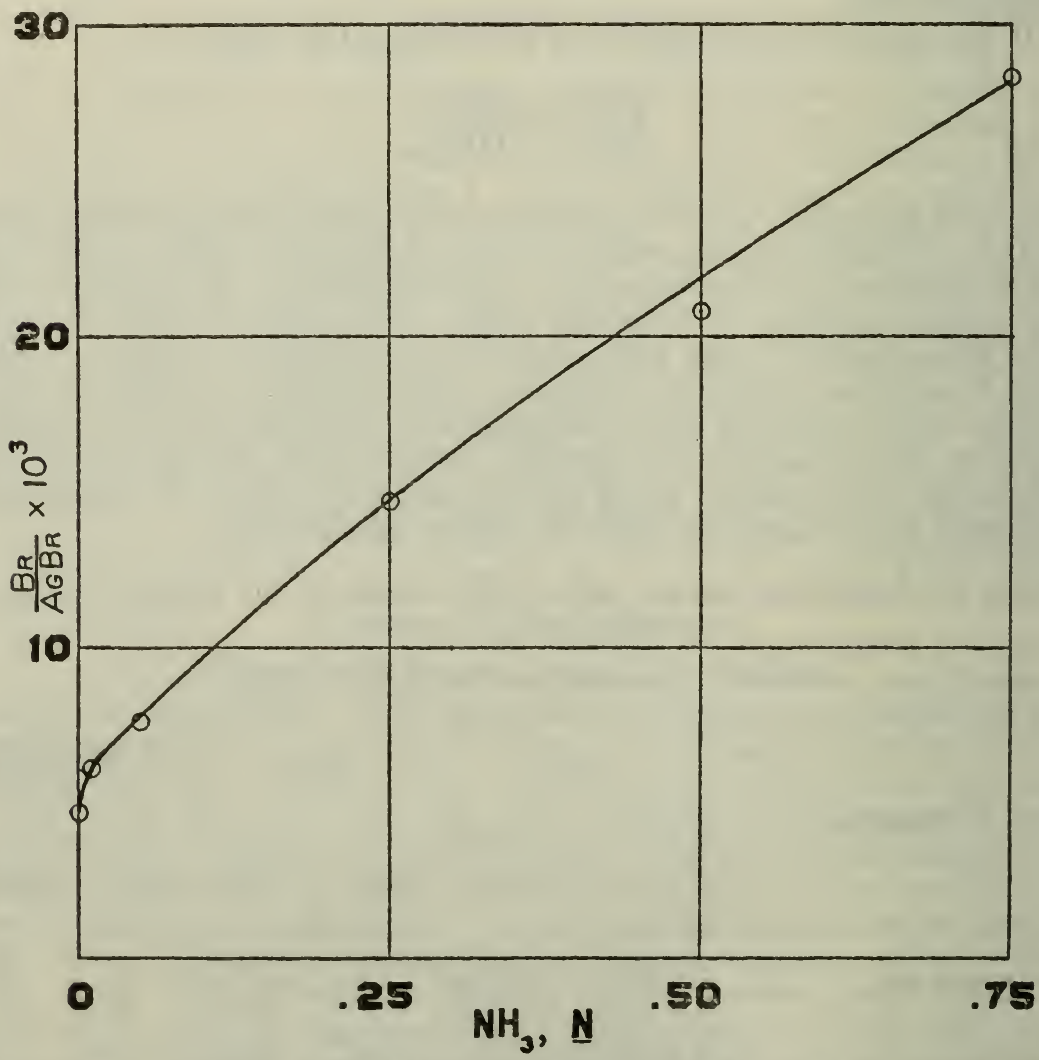

FIGURE 1.-Soluble bromide removed from Seed's 28 plates by bathing in solutions of ammonia

Ordinates, ratio of soluble bromide to silver bromide; abscissæ, concentration of ammonia.

cyanide according to the methods of Eggert (15) or Marasco (16). The data in the figure show that approximately 1 per cent of the silver bromide in the emulsion is decomposed by bathing in $0.25 \mathrm{~N}$ ammonia solution, the quantity increasing with ammonia concentration as would be expected. The existence of the excess silver in bathed plates is readily detected analytically. For example, Seed's 23 plates were given three successive extractions with $0.75 \mathrm{~N} \mathrm{NH}_{3}$, the sum of the soluble bromide in the extracts being 2.97 and 3.17 per cent of the total bromide in the emulsion. Nonhalide silver in the emulsion was then determined by cyanide extraction (14) to be 2.30 and 2.38 per 
cent of the total silver. The differences, 0.67 and 0.79 per cent are slightly larger than the soluble bromide originally present in the emulsion, 0.47 per cent by water extraction. Similar results wero obtained with other emlusions demonstrating that the emulsion is left with an excess of silver over halogen corresponding to the excess of soluble bromide found in the ammonia extract over tho soluble bromide originally present in the plate. Analysis of the complete emulsion for total silver and halogen by Clark's method (25) also proved that the soluble bromide found in the ammonia extracts of the Seed's 23 must have come from decomposition of the silver bromide, since no such amounts of soluble bromide were originally present in the emulsion.

The data of Table 1, columns 3 and 4, show that the commercial panchromatic emulsions were left with an excess of 0.2 to 1.0 per cent of silver over halogen after the ammonia treatment which produced the indicated photographic effects. The single extraction with water left the emulsions with a chemically negligible excess of either bromide or silver. As the increase in bromide extracted by the ammonia solution is the result of decomposition of silver bromide in consequence of the membrane equilibrium, the emulsion must have been left with an excess of silver equivalent to the difference between the ammonia and water extracts. It should be noted that the chloride extracted was the same whether water or ammonia was used, indicating that the emulsion closely approached equilibrium with the bath.

Having predicted and established that the result of bathing photographic plates or films with ammonia is to leave them with an excess of silver over halogen, proof of the mechanism of hypersensitization may be completed by comparison of the effects on sensitization produced by ammonia treatment and by addition of soluble silver salts to the emulsion.

\section{CORRELATION OF THE CHEMICAL AND SENSITOMET- RIC DATA ON HYPERSENSITIZATION}

In previous communications (2) (17) we have reported the effects of increasing the silver ion concentrations of emulsions by addition of soluble silver salts before coating. In the absence of sensitizing dyes, there was a slight increase in sensitivity at nomal values of $\mathrm{pH}$. Sensitization by dyes was found to be selectively increased by large amounts, so that the most characteristic change was an increase in relative sensitivity for the longer wave lengths. Sufficient increase in silver ion concentration, however, caused a decrease in sensitization by some of the basic dyes, which had been predicted by theoretical consideration of adsorption relations.

Data on the effect of ammonia treatment of emulsions sensitized with known dyes are presented in Table 5. These are representative of a considerable number of experiments; they were selected as far as possible to compare the behavior of different dyes in the same emulsion. It will be observed that in all cases sensitization by pinacyanol was increased by ammonia; this is also true for erythrosin, although the increase in one case was quite small. Sensitization by pinaflavol was decreased by ammonia in every case where the dyo was applied by bathing. In one emulsion, 4-103, the sensitivity passed through a maximum with increasing concentration of ammonia, 
corresponding to sensitization by pinaflavol with increasing silver ion concentration in the emulsion (2) which also passes through a maximum. This indicates that the failure of many commercial panchromatic emulsions to hypersensitize may be attributed to the characteristics of the dyes which are used. (Table 1.) Results with emulsion 4-128 are an exception; in the other experiments not recorded, hypersensitization of pinaflavol-sensitized emulsions occurred about one time in three. The sensitization by pinaverdol appeared to approach a maximum with increasing ammonia concentration, as would be expected from its behavior with increasing silver ion concentration.

\section{$\mathrm{T}_{\mathrm{ABLE}}$ 5.- - Hypersensitization with known dyes}

[Letters represent commercial emulsions which were bathed in the dye solutions, the ammonia being added to the dye bath. Figures represent experimental emulsions which were sensitized before coating and subsequently bathed with water or ammonia solutions]

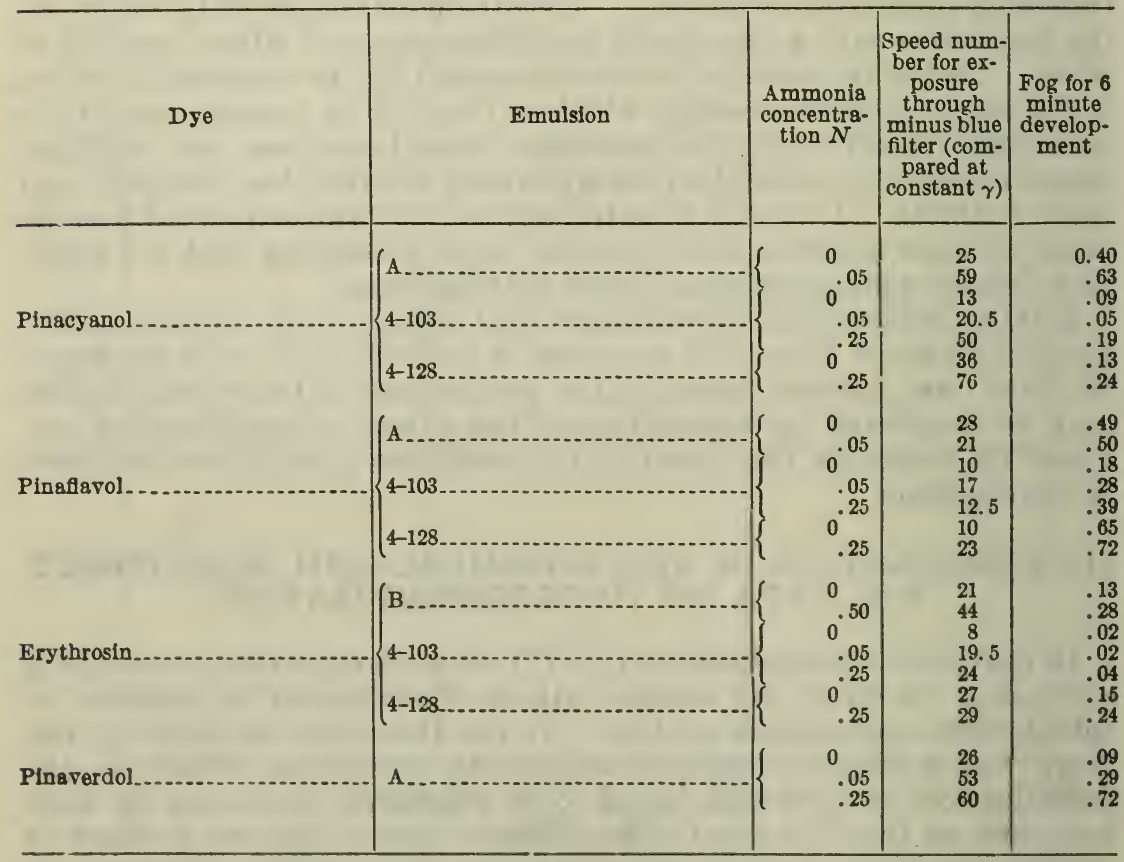

Other amines are capable of producing effects similar to ammonia, by the same mechanism. We have already reported the mild hypersensitizing action of pyridine (18). Extraction of Seed's 23 plates with $N / 2$ pyridine solution was found to remove soluble bromide equivalent to 0.66 per cent of the total bromide, indicating that the plate was left with 0.2 to 0.3 per cent excess silver. Triethanolamine has recently (19) been recommended for hypersensitizing. We have tested its action with pinacyanol and pinaverdol, and found that it is photographically equivalent to ammonia of lower concentration. Correspondingly, $0.25 \mathrm{~N}$ triethanolamine left a given emulsion with 0.3 per cent excess silver, and $0.25 N$ ammonia with 0.9 per cent excess. The lower alkalinity of triethanolamine is probably an advantage in cases where there is serious tendency to fog. 
Bokinik (20) has recently observed, by comparing plates bathed with water and with dilute silver nitrate solution, that increased silver ion concentration has little effect on sensitivity in the absence of dyes, but produced typical hypersensitization of panchromatic emulsions. He further demonstrated that it was not a development effect. We have also experimented with hypersensitization by bathing in dilute silver nitrate solutions; pinacyanol-sensitized emulsions were hypersensitized, and pinaflavol-sensitized emulsions were slightly decreased in speed, but the results were more difficult to reproduce than when the silver salts were added to the emulsion before coating.

As predicted theoretically, dissolved silver salts in an ammonia bath increase its effect without change in the mechanism; typical examples are given as part of the data in Tables 6 and 7 . In general, we have found little advantage in their use, as few emulsions are improved by silver ion concevtrations higher than those produced by bathing in $0.5 \mathrm{~N}$ ammonia. As the membrane equilibrium just discussed would not apply to a collodion emulsion, it would be necessary to add silver salts to the hypersensitizing bath to leave such an emulsion with excess silver.

The increased silver ion concentration produced by ammonia treatment is the principal factor in hypersensitization. However, others have been suggested, and some of these must be considered seriously.

Alkalinity tends to increase sensitization by some of the dyes, notably pinacyanol and erythrosin (2). The effect is not large. One per cent borax solutions ( $\mathrm{pH} 9.2$ ) were carefully compared with pure water as solvent for dyes and for after treatment of emulsions sensitized before coating; the difference was negligible. Of course, if the dye has been applied from an acid bath, as is recommended for kryptocyanine (21) and isocyanines (22), it is desirable to neutralize the remaining acid with some alkaline buffer, such as borax.

Jacobsohn (8) has suggested that treatment with ammonia may break down silver bromide-allyl thiocarbamide complex, thus forming new sensitivity nuclei of silver sulphide. He had originally observed in his extensive experiments on hypersensitization that some emulsions were much more affected by given treatment than others; comparison of otherwise similar emulsions made by the neutral ("boiled") and ammonia processes showed that the former was much better adapted to hypersensitization than the latter. As the neutral type of emulsion might be expected to contain more unchanged complex, he explained the difference between the emulsions on this basis. It is impossible to say that this does not occur, even with the short time and low temperatures of hypersensitization, especially as the reaction is accelerated not only by the ammonia, but by the increased silver ion concentration. The emulsions used for the experiments recorded in Tables 2 and 3 were such that appreciable quantities of unchanged complex might have been present, and the increase in sensitivity of the unsensitized portions on treatment with ammonia indicates that new nuclei may have been formed. However, Jacobsohn's hypothesis is inadequate as a complete explanation of hypersensitization. The experiments by Sheppard (1) on the effect of silver sulphide nuclei on sensitization by dyes, which were quoted by Jacobsohn in support of his hypothesis, show that the relative sensitivity to the longer wave lengths remains 
practically constant on the formation of nuclei. Experiments in this laboratory (2) have also indicated that the relative sensitivity is constant, or decreases, whereas an increase in this ratio is characteristic of hypersensitization. The large effects of bathing with pure water are certainly to be explained by extraction of soluble bromide rather than by formation of new nuclei, since no commercially stable emulsion could be appreciably ripened in the short time and low temperature of bathing and drying. The effects of ammonia appear to differ only quantitatively from those of water. No certain explanation of Jacobsohn's observations can be given, since the actual emulsions are not available. However, factors other than unchanged silver bromide-thiocarbamide complex may make neutral emulsions better adaptea to hypersensitization than those made by the ammonia process. Their $\mathrm{pH}$ is lower, so that more change both in hydrogen and silver ion concentrations would be produced by ammonia treatment. We have observed that under the same washing conditions ammonia process emulsions reach the lower bromide ion concentration, so that this may also reduce the change caused by the ammonia.

It has also been suggested that formation of silver nuclei by reduction of silver bromide might be a cause of hypersensitization. This explanation was used by Schmieschek (23) to account for hypersensitization by mixtures of silver salts and hydrogen peroxide. However, his conclusions are not supported by the experimental evidence. As far as can be determined by study of his publications, Schmieschek compared the plates treated with the mixed solutions only with untreated plates, and thus failed to observe that the hydrogen peroxide contributed nothing to the hypersensitization. His formulas were carefully tested on two emulsions, one of which, the Agfa Special Rapid panchromatic, had been used in his own experiments. The results are recorded in Tables 6 and 7. All the data in each table were obtained from plates which had been bathed under the same conditions of temperature, agitation, and time, dried together, and developed together after exposing. It is evident from the data that the ammonia-silver tungstate-hydrogen peroxide mixture was less satisfactory as a hypersensitizing bath than the ammonia alone, since at the best it produced no greater increase in sensitivity and the fog was higher. The same results were obtained in repeated tests. The peroxide decreased the effect of ammonia, and was of very doubtful advantage to the mixture of ammonia and silver salts, so that we are unable to agree with Schmieschek that it has any significant function. The Agfa plates were also bathed with mixtures of acetic acid, silver sulphate, and hydrogen peroxide as recommended by Schmieschek, and with the acid and silver sulphate, the plates being washed in faintly alkaline tap water after bathing. Both baths caused fog and desensitization, the decrease in sensitivity being greater from the mixture with the peroxide. Bokinik (24) also reports that he was unable to confirm Schmieschek's results, hydrogen peroxide decreasing rather than increasing the effect of silver salts. 
TABLE 6.-Hypersensitization of Agfa Special Rapid panchromatic plates (emulsion Q1666) by combinations of ammonia, silver tungstate, and hydrogen peroxide

\begin{tabular}{|c|c|c|c|c|c|}
\hline \multicolumn{3}{|c|}{$\begin{array}{l}\text { Composition of bath, } \\
\text { grams per liter }\end{array}$} & \multicolumn{3}{|c|}{ Speed at $\gamma=1.0$} \\
\hline$\underset{\text { nia }}{\text { Ammo- }}$ & $\begin{array}{l}\text { Silver } \\
\text { tung- } \\
\text { state }\end{array}$ & $\begin{array}{c}\text { Hydrogen } \\
\text { peroxide }\end{array}$ & $\begin{array}{l}\text { White } \\
\text { light }\end{array}$ & $\begin{array}{l}\text { Red } \\
\text { light }\end{array}$ & $\begin{array}{l}\text { Fog for 6- } \\
\text { minute } \\
\text { develop- } \\
\text { ment }\end{array}$ \\
\hline $\begin{array}{l}0 \\
.65 \\
.65 \\
.65 \\
.65\end{array}$ & $\begin{array}{l}0 \\
0 \\
0 \\
.14 \\
.14\end{array}$ & $\begin{array}{l}0 \\
0 \\
.75 \\
0.75\end{array}$ & $\begin{array}{l}265 \\
360 \\
380 \\
430 \\
320\end{array}$ & $\begin{array}{l}18 \\
38 \\
29 \\
31 \\
39\end{array}$ & $\begin{array}{l}0.15 \\
.23 \\
.28 \\
.41 \\
.66\end{array}$ \\
\hline
\end{tabular}

TABLE 7.-Hypersensitization of Wratten " $M$ " plates (emulsion 5173) by combinations of ammonia, silver tungstate, and hydrogen peroxide

\begin{tabular}{|c|c|c|c|c|c|}
\hline \multicolumn{3}{|c|}{$\begin{array}{l}\text { Composition of bath, } \\
\text { grams per liter }\end{array}$} & \multicolumn{3}{|c|}{ Speed at $\gamma=1.8$} \\
\hline$\underset{\text { nia }}{\text { Ammo- }}$ & $\begin{array}{l}\text { Silver } \\
\text { tung- } \\
\text { state }\end{array}$ & $\begin{array}{c}\text { Hydrogen } \\
\text { peroxide }\end{array}$ & $\begin{array}{l}\text { Blue } \\
\text { light }\end{array}$ & $\begin{array}{l}\text { Yellow } \\
\text { light }\end{array}$ & $\begin{array}{l}\text { Fog for 6- } \\
\text { minute } \\
\text { develop- } \\
\text { ment }\end{array}$ \\
\hline $\begin{array}{l}\text { Untreat } \\
0 \\
.65 \\
.65 \\
.65 \\
.65\end{array}$ & $\begin{array}{l}\text { plate.. } \\
0 \\
0 \\
0 \\
.14 \\
.14\end{array}$ & $\begin{array}{l}0 \\
0 \\
0.75 \\
.75\end{array}$ & $\begin{array}{r}10.5 \\
11.5 \\
15.2 \\
9.2 \\
9.7 \\
13.5\end{array}$ & $\begin{array}{r}59 \\
86 \\
180 \\
85 \\
140 \\
145\end{array}$ & $\begin{array}{l}0.13 \\
.20 \\
.33 \\
.22 \\
.33 \\
.34\end{array}$ \\
\hline
\end{tabular}

Bokinik (24) reports that both panchromatic and unsensitized plates were increased in sensitivity by bathing with 0.1 per cent $(0.02 M)$ solutions of hydrazine hydrate. A reference in the summary of his paper indicates that other reducing agents were used, but no others are mentioned in the text. Bokinik's experiments with hydrazine were repeated with a number of commercial and experimental emulsions, some of the data being given in Tables 2 and 3. It was found necessary to use more dilute solutions than his; 0.001 to $0.0015 M$ gave at least as much increase in sensitivity as stronger solutions, and less fog. Commercial unsensitized emulsions such as the Eastman 33 were not increased in sensitivity by either hydrazine or ammonia. The effect of the hydrazine on the unsensitized portions of experimental emulsions $4-143$ and $4-145$ (Tables 2 and 3 ) was quite small, so that it is improbable that it produces new sensitivity nuclei of silver. The pinacyanol-sensitized portions of emulsions 4-143 and 4-145 were hypersensitized by the hydrazine, the action being similar to that of ammonia, but considerably less. Similar results were obtained with Eastman infra-red sensitive plates (emulsion 5,875).

The hypersensitizing action of the hydrazine is greater than can be explained by its alkalinity alone. Analysis of $0.0015 M$ hydrazine hydrate solutions which had been used for bathing plates showed that they had extracted practically no more bromide than water, so that the increase in silver ion concentration in the emulsions, compared 
to that produced by water, was negligible. Formation of new sensitivity nuclei by reduction of the silver bromide was improbable because the sensitivity to the longer wave lengths was selectively increased. It is possible that the increase in reduction potential of the emulsion can cause a moderate amount of hypersensitization. In order to test this hypothesis without the complications of membrane equilibria introduced by bathing the plates, small amounts of hydrazine and other reducing agents were added to sensitized emulsions just before coating. In this case, however, the reducing agent comes in contact with the warm liquid emulsion followed by a relatively slow drying, and a concentration of reducing agent producing a given potential may cause fog when it would not do so at the low temperature and short drying period used in bathing; for example, hydrazine at five times the maximum concentration given in Table 8 was found to cause heavy fog, although this amount made the liquid emulsion only $0.0010 M$ with respect to the hydrazine. The data are given in Table 8 , omitting negative results with sodium arsenite and hydroxylamine hydrochloride. Ammonia is included in this table for comparison with the results obtained by bathing similar emulsions (as 4-145) with ammonia, not because it was considered to have appreciable reduction potential. The increase in sensitivity is about what might be expected from the increase in $\mathrm{pH}$, which amounted to one unit, and is of a lower order of magnitude than the effect of bathing with ammonia solutions with the resulting membrane equilibrium.

\section{TABLE 8.-Effect of reducing agents on sensitization by dyes}

[Speed numbers are relative values, obtained by exposure through the Wratten filters only, without the Davis-Gibson correction filter; all values for development to $\gamma=1.0$. "B" (green) filter used for erythrosin-sensitized emulsion; "A" (red) filter for pinacyanol-sensitized]

\begin{tabular}{|c|c|c|c|c|c|}
\hline Dye & Reducing agent & $\begin{array}{l}\text { Molar } \\
\text { ratio, } \\
\text { reducing } \\
\text { agent to } \\
\text { silver } \\
\text { halide }\end{array}$ & $\begin{array}{c}\text { Speed } \\
\text { through } \\
\text { "C" } \\
\text { (blue) } \\
\text { fliter }\end{array}$ & $\begin{array}{l}\text { Speed } \\
\text { through } \\
\text { "B" or } \\
\text { "A" } \\
\text { filter }\end{array}$ & $\begin{array}{c}\text { Ratio } \\
\text { of speed } \\
\text { num- } \\
\text { bers }\end{array}$ \\
\hline $\begin{array}{l}\text { Erythrosin.. } \\
\text { Pinacyanol. } \\
\text { Pinacyanol. }\end{array}$ & $\begin{array}{l}\left\{\begin{array}{l}\text { Control } \\
\text { Ammonia_ } \\
\text { Sodium sulphite }\end{array}\right. \\
\left\{\begin{array}{l}\text { Ammontrol } \\
\text { Amia } \\
\text { Sodium sulphite }\end{array}\right. \\
\left\{\begin{array}{l}\text { Control } \\
\text { Hydrazine } \\
\text { Iydrazine } \\
p \text {-hydroxyphenylglycine }\end{array}\right.\end{array}$ & $\begin{array}{l}0^{0} \\
1.3 \times 10^{-2} \\
1.3 \times 10^{-2} \\
0 \\
1.3 \times 10^{-2} \\
1.3 \times 10^{-2} \\
0 \\
2.8 \times 10^{-1} \\
1.1 \times 10^{-8} \\
1.5 \times 10^{-8}\end{array}$ & $\begin{array}{r}125 \\
130 \\
155 \\
64 \\
75 \\
75 \\
37 \\
43 \\
53 \\
60\end{array}$ & $\begin{array}{r}54 \\
55 \\
87 \\
165 \\
215 \\
265 \\
130 \\
175 \\
180 \\
170\end{array}$ & $\begin{array}{l}0.44 \\
.43 \\
.56 \\
2.6 \\
2.9 \\
3.5 \\
3.5 \\
4.0 \\
3.4 \\
2.9\end{array}$ \\
\hline
\end{tabular}

The positive results with hydrazine, sodium sulphite and "Glycine" indicate that reducing agents may produce some increase in sensitization by dyes, even though they are without effect on the unsensitized emulsion. Control experiments demonstrated that neither sodium sulphite nor hydrazine added in these quantities and under these conditions increased the sensitivity of similar emulsions in the absence of dyes. This is at least consistent with the simple chemical theory of sensitization which we advocate as the best starting point for a complete theory. If the reduction potential of the emulsion is increased, activation of the dye by light might be expected to 
cause more reaction with the silver bromide. It should be understood, however, that in admitting the possibility of hypersensitization by reducing agents, we do not accept this as the explanation of hypersensitization by ammonia or amines, or combinations of ammonia or amines with soluble silver salts. The much greater hypersensitization produced by the latter class of materials is caused by increase in the silver ion concentration of the emulsion, as the result of membrane equilibrium followed by drying with the removal of the ammonia or amine. In this case there has been an increase in the oxidation potential of the silver bromide by adsorption on it of free silver ions, instead of increase in the reduction potential of its environment.

Knowledge of the mechanism of hypersensitization serves to point out the inherent limitations of the process rather than to suggest improvements in procedure. Increase in sensitivity is necessarily gained at the expense of stability; the optimum excess of silver, which may be controlled by the ammonia concentration, depends on the use to be made of the hypersensitized material. In general, the more rapid the drying the higher concentration of ammonia may be used. Addition of alcohol to the bath aids in drying; it decreases the effect of a given concentration of ammonia by decreasing the dissociation, so that it is generally better to use aqueous solutions, followed by soaking the plate in 95 per cent alcohol to accelerate drying. Attempts to improve the stability of bathed plates by adding bromide to the dye bath must necessarily do so at the expense of sensitivity, since the effects of the ammonia and the bromide are opposed to each other. As soluble bromide is shown to accumulate in hypersensitizing baths or dye baths, it is obvious that their effectiveness will rapidly fall off with use, even though the ammonia concentration remains practically the same. Combination of silver salts with ammonia is little different from the use of higher concentrations of ammonia, although it may be preferable if it desired to avoid high alkalinity; difficultly soluble silver salts, such as the chloride or tungstate, are preferable to silver nitrate, since the maximum silver ion concentration which they can produce is limited by their solubility and there is less danger of fog from use of an excess.

\section{ACKNOWLEDGMENTS}

C. M. Kretchman has rendered valuable assistance in the sensitometric work, in coating the experimental emulsions, and in some of the bathing experiments.

\section{LIST OF REFERENCES}

1. Sheppard, Colloid Symposium Monograph, vol. 3, p. 1, 1925.

2. Carroll and Hubbard, B. S. Jour. Research, vol. 9 (RP488), p. 529, 1932.

3. Schumann, Phot. Wochenbl., p. 395, 1885, and p. 49, 1886.

4. Dieterle, vol. 3-3, Sensibilisierung und Desensibilisierung, p. 227.

5. Burka, J. Frank. Inst., vol. 189, p. 25, 1920.

6. Walters and Davis, B. S. Sci. Paper No. 422.

7. Wall, History of Three-Color Photography, p. 222.

8. Jacobsohn, Zeit. f. wiss. Phot., vol. 27, p. 19, 1929, also "Theoric und Praxis der Utbersensibilisierung."

9. Carroll and Hubbard, B. S. Jour. Research, vol. 8 (RP430), p. 481, 1932.

10. Donnan, Zeit. f. Elektrochemie, vol. 17, p. 572, 1911. 
11. Carroll and Hubbard, B. S. Jour. Research, vol. 7 (RP376), p. 811, 1931.

12. Lüppo-Cramer, Phot. Ind., vol. 14, pp. 78, 111, 1916.

13. Mitchel and Rawling, Proc. 8th Int. Cong. Phot., p. 56, 1932.

14. Carroll and Hubbard, B. S. Jour. Research, vol. 8 (RP447), p. 711, 1932.

15. Eggert, Zeit. f. wiss. Phot., vol. 22, p. 209, 1924.

16. Marasco, Ind. Eng. Chem., vol. 16, p. 945, 1924.

17. Carroll and Hubbard, J. Soc. Motion Picture Eng., vol. 18, p. 600, 1932.

18. Carroll and Hubbard, B. S. Jour. Research, vol. 4 (RP173), p. 693, 1930.

19. Mees, J. Opt. Soc. Am., vol. 21, p. 753, 1931.

20. Bokinik, Zeit. f. wiss. Phot., vol. 30, p. 322, 1932.

21. Dundon, Am. Phot., vol. 20, p. 670, 1926.

22. Von Hübl, Koll. Zeit., vol. 27, p. 263, 1920.

23. Schmieschek, Phot. Ind., vol. 28, pp. 445, 472, 1930.

24. Bokinik, Zeit. f. wiss. Phot., vol. 30 , p. 330, 1932.

25. W. Clark, J. Chem. Soc., p. 749, 1925.

Washington, November 23, 1932. 